\title{
Perceived Effectiveness of Extranets in Open and Distance Learning (ODL) Institutions: Students' and Lectures' Perspectives
}

\author{
Rendani Sipho Netanda \\ University of South Africa \\ Email: netanrs@unisa.ac.za
}

Hemduth Vijay Rugbeer

University of Zululand

Email:RugbeerH@unizulu.ac.za

Gedala Mulliah Naidoo

University of Zululand

Email: NaidooG@unizulu.ac.za

Doi:10.5901/mjss.2014.v5n20p1293

\begin{abstract}
This survey examines the perceived effectiveness of an extranet within an open distance learning institution from the students' and lecturers' perspectives. It is underpinned by the uses and gratifications theory and followed a mixed-methods approach in which quantitative and qualitative methodologies were adopted. Purposive sampling technique was employed to sample the academics while the sample size of 400 students was reached using the randomizer available on the internet. Participants were 2 academics and 350 students who were registered in 2013 for their second and third year level. The response rate was $88 \%$. A questionnaire was used to collect data from the students while the in-depth interviews were held with the academics. While quantitative data was analysed using statistical Package of Social Science Research (SPSS) version 18, qualitative data was analysed using thematic categorization. The findings showed that while extranet presents numerous challenges when used as a technological learning and teaching pedagogy, it is viewed as an effective communication tool in ODL institutions.
\end{abstract}

Keywords: Extranets, Perceived effectiveness, Open Distance Learning, myUnisa

\section{Introduction}

Literature reveals that extranets is, and continues to pose challenges for post school systems, particularly in open distance learning institutions (Murphy and Cifuentes, 2001:285; Emmanuel and Ngiye, 2011:230). This is a crosssectional mixed-methods study to determine the perceived effectiveness of an extranet as an electronic communication medium between the university and students. The aim is to determine the degree to which an extranet can help students meet their expectations in ODL institutions. This study use a case of UNISA extranet called myUnisa. UNISA is an ODL institution whose mode of teaching requires that students use (in addition to traditional modes of learning) new media technologies such as the internet, intranet and extranet in learning processes. Driven by the technological advancement, UNISA responded to the changes emanating from the technological environment by developing myUnisa extranet to facilitate communication between the university and its students. MyUnisa is a two-way communication channel, enabling UNISA and students to share information through interactive online forums. Although the use of technology may help the students in learning, it may presents a number of problems to students if they lack necessary skills to use them and this may negatively affect the students' learning (Emmanuel and Ngiye 2011:230). According to Emmanuel and Ngiye (2011:230), online technology presents a challenge to the students because it requires basic computer literacy skills. Murphy and Cifuentes' (2001:285) study revealed similar findings that acknowledge that Web-based courses present challenges to students who do not know how to use Web tools. This research seeks to answer a core question:

What perspectives are of the students and lecturers on the effectiveness of the extranet as a pedagogical mode for learning and teaching in an open distance learning institutions? 


\section{Historical Background of the Extranet}

The origin of the extranet has been through a need identified by the commercial organisations to efficiently engage them into a business-to-business electronic commerce. Oppong, Yen and Merhout (2005:417) are of the view that the extranet technology evolved from the intranet as a business-to-business (B2B) communication tool. Similar to this view, Maier (2013:1) posits that the extranet originated from different business entities that needed to adopt an e-commerce approach in conducting their activities. It is a result of a combination of local area networks (LANs) and wide area networks (WANs) (Maier 2013). According to Oppong, et al (2005), the intranet evolved from the public internet. By its very nature an extranet was designed to promote open, interactive and collaborative working environment between a partnership of different businesses (Healy and Iles, 2002:120).

Commercial organisations needed to share certain proprietary information with the clients, customers and suppliers or businesses in partnerships. Extranets, referred to as extended intranets that use the internet technology, provide access to those external clients such as contractors, distributors, customers and business partners of the organisations to a range of information such as the available products, their prices, and how to order them online (Angeles, 2001:168; Vlosky, Fontenot and Blalock, 2000:438-439). Angeles describes extranets as the use of intranets to connect two businesses in order to foster communication and transactions between them. Viewed from the commercial context, Cameron (1998) deduces that extranets are e-commerce branches through which corporations share information with business partners, distributors, or customers.

The evolution of the extranet had been through what Mills (1998:1) call "waves". Mills believes that the extranet is the third wave which followed the second wave, referred to as the intranet. The first wave was characterised by the internet and the World Wide Web (www). The internet is capable of providing the public with wide range of information on any topic. The information accessible through the internet can be any types of text, documents, images, pictures, video, animation and sound.

Using the internet and World Wide Web protocols, organisations realised they could benefit from developing their own internal internets, which then became known as the intranets to refer to organisations' internets for the dissemination of information to and communications with distinct internal employees and other structures of the organisation. Mills (1998:3) believes that the intranet became efficient and effective in the management of the organisation. The need by companies to use web-based technology as a business strategy, marketing tool and for operations resulted in the 'birth' of the extranet. Mills called the extranet the third wave, referring to the third stage in the developmental process of online technology which became a pivotal communication channel for the dissemination of the information relating to the organisation's products or services. This third wave in the evolution of the extranet is synonymously called the 'extended intranet' (Mills, 1998:3) which tended to extend the access of organisation's information to the authorised trading partners and customers located outside the corporate firewall. The extranet evolved because of certain anticipated function of importance to the functioning and the running of the business organisations. Since the discussion of this study is around the extranet, it is fundamental to scrutinise what it is.

\section{Theoretical Framework}

The theory of uses and gratifications had been widely recognised and used since from the early 1950s and later 1960s and was basically rooted from the need to address the effects media have on people after they have been exposed to the mass media campaigns (Leung and Wei, 2000:4). According to Cummings (2008:2-4), uses and gratifications theory was first coined by Jay Blumler and Elihu Katz in 1974 and examines why people choose certain media and disregards others.

The uses and gratifications theory is widely recognised in the field of communication, particularly in media studies. Several studies proved that the uses and gratifications theory is crucial in explaining how people use their different media and how such media meet their expectations and needs. Research done by Raacke and Bonds-Raacke (2008:171) on the application of uses and gratification theory to explore friend-networking sites about MySpace and Facebook found that $90 \%$ of the respondents uses MySpace and Facebook to keep in touch with their old friends. It also found that $13.9 \%$ of the respondents use MySpace and Facebook for academic-focused communications.

The review of the literature revealed that the uses and gratifications theory have been applied by media and communication scholars to both the traditional media (such as newspapers, magazines, televisions and radios) and to the modern media technologies (such as the internet and its applications like intranet and extranet) (Shao, 2009:9). 


\subsection{Application of uses and gratifications theory in extranet}

Extranet is a communication channel in which information between partners can be accessed and exchanged. It is an epitome of the new media technologies or the so-called information communication technologies, and can therefore be regarded as a media. It is therefore appropriate, though borrowed from media studies, to use it to explain how myUnisa extranet is used and experienced by the students and the different UNISA structures as a communication channel. UNISA uses different delivery modes of the study materials and transmission of certain information to its students. It delivers books in electronic and hard copy formats as well as other information in the form of podcast, DVDs and CDs. This study examines myUnisa extranet as a communication channel, looking at how students and staff members use it and the degree to which they perceive it effective for learning and teaching purposes.

Since its inception, uses and gratifications (U\&G) theory had been used to explain why people use a particular media. People use different media to meet certain personal interests. It is therefore important to discuss some general reasons for the application of this theory in the use of internet and its applications (extranet and intranet). Papacharissi and Rubin (2000), proposed an interpersonal communication gratification. This implies that intranet, extranet and the public internet works like chartrooms, e-mail and even discussion forums. In addition to this gratifications, Flanagin and Metzger (2001:162-173) identified other dimensions of gratifications as the need to solve problems, gain status, build and maintain relationship, acquire personal insight into something and to persuade others. Extranet had been widely used to sell products and persuade customers to buy or use the organisation's services. In HEls, extranet is used to for communications with the students and subsequently becomes a channel to build and maintain a good relationship with the lecturers.

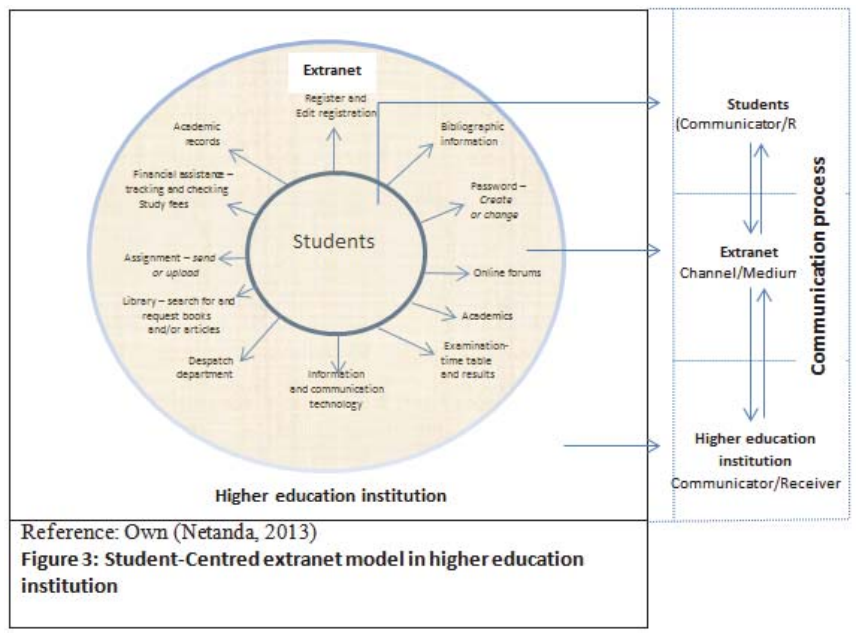

The study analysed the UNISA's extranet known as myUnisa. The seven key components of myUnisa extranet which were analysed in this study were edit registration, examination results, examination time table, financial tracking, bibliographic details, study fees quotations, academic records and change password. This proposed model in figure 14 postulates that in order to successfully implement an educational extranet in higher education institutions, consideration should be made during the development stage of the extranet to include aspects or hyperlinks shown in the extranet sphere of the model.

There are three elements of the communication process as postulated by the module in figure 14. The first element (the outer sphere) is the higher education institutions as a participant in the communication process. The second element (the middle sphere) in the model is the channel or a communication tool through which information is shared between the students and the higher education institution. The third element (the York or most inner sphere) is the student. The model suggests that HEls's extranets are to be effective if communication between the institutions and their students is two-way. Both the HEls and their students must exchange roles in the communication process. Each of them can either fulfil a role of a communicator or a receiver or both during a particular time in the process of teaching and learning. The model further suggests that it must be student-centred, implying that both the development and the implementation of extranet in HEls must be executed with students in mind to ensure the betterment in learning. This own depicted extranet model believes that students should have a range of hyperlinks to access information significant to know when learning in HEls. 
This conforms well to the core stance of the uses and gratification (U\&G) theory which informed this study, that people use a particular media for different purposes, for serving different interests and for meeting different expectations. In this study, the results also revealed the relevance of the U\&G theory when the larger group of students responded that their usage of the UNISA's extranet depends on what they want (refer to figure 7 - Pie Chart showing the frequency of use of myUnisa).

The proposed student-centred extranet model in HEls can be classified as what Riggins and Rhee (1998) refer to as an Intronet because it permits the organisation's external stakeholders to have a controlled access behind the organisation's firewall into the intranet. Similarly, this model holds the view that students have to be granted permission to access information related to what they are learning or information applicable to them as students. Furthermore, this model has a trait of a type of extranet which Rainer and Cegielski (2009:345) named a 'company and its dealers, customers, or suppliers'. Organisations implementing a 'company and its dealers, customers, or suppliers' must provide dealers, customers and suppliers with an access to the organisation's information. The uniqueness of the student-centred extranet model in terms of its characteristics, nature and applicability in higher education institution suggests that in addition to the types of extranet identified by Rainer and Cegielski (2009) and Riggins and Rhee (1998), a new type is required to reflect the context of its application, its purpose and for whom they are implemented. This type of extranet (figure 14) is the 'higher education institution (HEI)-student extranet'. It is specifically for higher education context, and it is designed for the communication with the students.

\section{Methodology and Research Design}

A researcher's methodology determines the way in which research methods will be used and it is derived from the assumptions of the researcher about the phenomenon under investigation (Hesse-Biber, 2010:456). In her attempt to distinguish a methodology and a method, Hesse-Biber describes methods as tools and a methodology as the design which serves to inform the researcher how such methods will be used.

The quantitative phase of this research was conducted between 25 May 2013 and July 2013. This study considers research methods as aspects of the research, such as qualitative and quantitative; positivist and interpretive paradigms; as well as a survey (self-administered questionnaire) and interviews. The study refers research methodology to designing the study in two phases in which the first phase is quantitative, meaning it is positivist-oriented and collects data using survey whilst the second phase becomes qualitative, meaning it is interpretive-oriented and collects data using interviews. As part of the research design to be followed in this study, two data collection methods were used, with the first one being the questionnaire distributed to students and the second one being in-depth interviews conducted with academics.

The research methodology followed in this study was mixed-methods. Mixed-methods is a research that has a purpose of providing a better understanding of the phenomenon under investigation by emphasizing integration of quantitative and qualitative methods which include collecting and analysing data using quantitative and qualitative methods (Ivankova, Creswell and Stick, 2006:3).

Various authors on mixed-methods use different concepts to refer to mixed-methods. For example, Johnson, et al. (2007:112-133) call it mix research, and Johnson and Onwuegbuzie (2004) refer to mixed-methods as an integrative research. However, all these different concepts emphasise mixing of different quantitative and qualitative techniques and methodologies in research (Bazeley, 2009:203 and Netanda, 2012). There is still no consensus amongst the community of practice regarding the definition of mixed methods research (Truscott, Swars, Zhao, Dooley, Williams, Hart, Matthews, Swars, Smith, Thornton-Reid, 2010:318). For the purpose of this study, mixed methods is understood from Johnson, Onwuegbuzie and Turner's (2007:123) perspective as they describe it as a research in which an investigator or group of investigators combine methods of quantitative and qualitative research approaches for the purpose of collaboration, breadth and depth of understanding the problem under investigation within a single study.

\subsection{Research methods}

This research drew from both quantitative and qualitative approaches and methods. For example, the self-administered questionnaire consisted of quantitative (close-ended) and qualitative (open-ended) questions even though quantitative questions were predominately used over qualitative ones. The theory from the literature review had been from quantitative and qualitative research to reflect multiple epistemological stances towards studying the same or related phenomenon. Inferences were drawn from the quantitative and qualitative findings derived from phase 1 and 2 with phase 1 being quantitative-based and phase 2 being qualitative-based. The survey (self-administered questionnaire) and 
an interviews were used to gather data. Interviews with the academics were expected to reveal the understanding of them about the impact or effectiveness myUnisa has on students as an online communication medium and a technological pedagogy for teaching and learning.

The reason for the integrated use of these traditional contrasting methodological paradigms (Quantitative and a qualitative) in this research was as follows:

- to have the results of one methodology complementing that of the other;

- $\quad$ to provide different worldviews to study the perceived impact of myUnisa as an electronic communication medium on students' mode of learning; and

- $\quad$ to provide the basis for the development of the second phase.

Hessen Bibber (2010:457) refers to such rationale behind the implementation of mixed methods as "triangulation" in which the aim of the mixed-methods design is to validate the quantitative statistical findings with qualitative findings.

\subsection{Research design (strategic framework)}

This study employed mixed-methods sequential explanatory research design. Mixed-methods sequential explanatory research design is one of the six types of mixed-methods (Creswell, Plano Clark, Gutmann and Hanson, 2003) which has been considered to be a third methodological movement (Johnson, Onwuegbuzie and Turner, 2007:113, 117). It is described as the research process in which quantitative data is collected and analysed prior to collecting and analysing qualitative data within a single study (Ivankova, et al. 2006:3-4).

The study went through two phases. The first phase was quantitative-based and had employed a positivist paradigm. It was through this phase that the researcher was able to determine secondary purposes of this study. The second phase was qualitative-based and had employed an interpretive paradigm. The collective interpretation or conception of the integrated use of positivist and interpretive approaches within a single study lead to the philosophy of 'pragmatism' that places an emphasis on the use of different perspectives to seeing, knowing and interpreting a phenomenon under investigation within a single study (Green, 2007; 2008).

The interview guide or schedule was developed based on findings found from the first phase. This makes 'development' one of the reasons for choosing Mixed-methods sequential explanatory research design. In this study, the mixing of quantitative and qualitative techniques overlapped, with the first phase predominately quantitative. For example, the survey comprised of predominately close ended-questions (quantitative) and fewer open-ended questions (qualitative). In the second phase, the interview guide comprised fewer close-ended questions and more open-ended questions. This was done to explore more on the research problem leading to an in-depth description of the phenomenon.

The integrated use of these two different research methodologies makes the study mixed (Bazeley, 2009:203) and the purpose of this mixed-method sequential explanatory design which begins with quantitative approach is 'development' - which allows the development of the interview guide from the findings of the phase of the study.

Another purpose to use this design was 'complement'- which allows the results from the two consecutive phases to validate the results determined through each of the methodology. The rationale for choosing this design stems from the need to use multiple perspectives for development and complementary purposes (Green, 2008) and to draw from strengths of quantitative and qualitative techniques and reduce their limitations (Johnson and Onwuegbuzie, 2004).

\subsection{Sample and sampling methods}

\subsubsection{Phase 1: quantitative-based}

A list (sampling-frame) of the 2013 registered students at second and third year level was sought from the university (UNISA). 400 students were sampled using the randomiser available on the internet. 350 students managed to complete the self-administered questionnaires. The response rate was $88 \%$.

The reason for purposively choosing participants from the 2013 second and third year and level was that they would have gained experience in the functioning of myUnisa extranet as an electronic media, pedagogy for learning and teaching and as a communication medium.

\subsubsection{Phase 2: qualitative-based}

In-depth interviews were conducted with key informants from UNISA department of communication Science. Babbie and 
Mouton (2001:168) refer to informants as members of the group (for instance, staff members) "who can talk directly about the group per se". In this study, key informants are the academics who usually interact with students through myUnisa extranet and have experiences on how it works. The study had engaged two lecturers from a group that has at least three years' experience in interaction with the students through myUnisa extranet.

\subsection{Target population}

Population refers to the overall group of elements from which selection of participants is derived (Babbie and Mouton, 2001:174). The concept target population was used synonymously to refer to the population. The target population in this study is the UNISA students. The results were generalised to these students.

\subsection{Units of analysis}

Units of analysis, also known as sampling units, refer to those characteristics of the elements that the researcher bases the selection of the elements on (Babbie and Mouton, 2001:174). The following are sampling units taken into consideration for the selection of the students to participate in the research:

Students registered for second and third year level in 2013;

Students who use myUnisa, UNISA's extranet

Second and third year students because they would have gained insight into how myUnisa works; and

Only students located in South Africa in 2013.

This means that the students selected include degree candidates, non-degree candidates, and undergraduates, postgraduates, part-time and full-time.

The following sampling units were used to select the staff members:

A lecturer (academic); and

Who have at least worked for a period of three years as a lecturer at university of South Africa

Who have been using myUnisa extranet for communications with the students

\subsection{Data Collection}

Data was collected using the questionnaires which were distributed electronically to the sampled students. Students completed the questionnaires and returned them back using e-mails. Each of them participated on a voluntary basis and all ethical principles were applied. Data from the academics were collected through an in-depth interviews held in their offices. Interviews lasted for approximately an hour and all ethical principles were also followed.

\subsection{Analysis and interpretation}

Descriptive and thematic analyses were used. Interpretation was based on findings obtained through using quantitative approach in phase 1 in integration with those obtained from qualitative approach in phase 2.

\section{Findings and Discussion}

\subsection{Findings: Quantitative phase}

\subsubsection{Students' demographic information}

The results of the study revealed that out of 350 respondents, there were a total of 147 males and 203 females. Males contributed to the total number of respondents with $42 \%$ while the females contributed with $58 \%$. This means that a larger student population that participated in the study was females. It was interesting to note that many of the respondents were Blacks which amounted to a total of 195 , whilst Whites were 75 , Indians were 47 and Coloured were only 33 . Of the 195 blacks, 107 respondents were found to be females whilst only 88 represented male respondents. Black male respondents contributed $45.1 \%$ to the total number of the black respondents, and black female respondents contributed $54.9 \%$ to the total number of black respondents. In addition, black male respondents had a contribution of $59.9 \%$ to all black respondents which counted to a total of 195.

Black female respondents were represented by $52.7 \%$ within 195 black respondents. Black male respondents 
contributed $25.1 \%$ to the total respondents of 350 while black female respondents contributed $30.6 \%$. The combined percentage of black male and female respondents had a contribution of $55.7 \%$ to the entire number of the respondents in the study. Of the 195 black respondents, 26 (13.3\%) were of the age group of 15-20 years of the total black respondents, $37(19 \%)$ were aged between 21 and 25 years, 35 (17.9\%) were aged between 26 and 30 years, 53 (27.2\%) were aged between 31 and 35 , and 44 (22.6\%) were 36 years and older. This means that amongst black respondents, there were many respondents from the age group of 36 years and older, contributing $65.7 \%$ to the total number of respondents (67) in the whole age group of ' 36 years and older' and $12.6 \%$ to the total number of respondents who participated in the study. However, many of the respondents across all the age groups were found to be within the 31-35 years category with a count of 91 and $26 \%$ contribution to the total of 350 respondents.

Table 1: Representation of respondents' gender from ethnic groups

\begin{tabular}{|c|c|c|c|c|c|}
\hline \multicolumn{3}{|l|}{ Ethic Group } & \multicolumn{2}{|c|}{ Respondent's gender } & \multirow{3}{*}{\begin{tabular}{|l} 
Total \\
350
\end{tabular}} \\
\hline & & & \multirow{2}{*}{$\begin{array}{l}\text { Male } \\
147 \\
42.0 \%\end{array}$} & \multirow{2}{*}{\begin{tabular}{|l|} 
Female \\
203 \\
$58.0 \%$ \\
\end{tabular}} & \\
\hline Total & & $\begin{array}{l}\text { Count } \\
\text { \% within Ethic Group }\end{array}$ & & & \\
\hline & Black & $\begin{array}{l}\% \text { within Respondent's gender } \\
\% \text { of Total } \\
\text { Count } \\
\% \text { within Ethic Group } \\
\% \text { within Respondent's gender }\end{array}$ & $\begin{array}{l}100.0 \% \\
42.0 \% \\
88 \\
45.1 \% \\
59.9 \% \\
\end{array}$ & $\begin{array}{l}100.0 \% \\
58.0 \% \\
107 \\
54.9 \% \\
52.7 \% \\
\end{array}$ & $\begin{array}{l}100.0 \% \\
100.0 \% \\
195 \\
100.0 \% \\
55.7 \% \\
\end{array}$ \\
\hline \multirow[t]{3}{*}{ Ethnic Group } & White & $\begin{array}{l}\% \text { of Total } \\
\text { Count } \\
\% \text { within Ethic Group } \\
\% \text { within Respondent's gender } \\
\% \text { of Total }\end{array}$ & $\begin{array}{l}25.1 \% \\
32 \\
42.7 \% \\
21.8 \% \\
9.1 \%\end{array}$ & $\begin{array}{l}30.6 \% \\
43 \\
57.3 \% \\
21.2 \% \\
12.3 \%\end{array}$ & $\begin{array}{l}55.7 \% \\
75 \\
100.0 \% \\
21.4 \% \\
21.4 \%\end{array}$ \\
\hline & Indian & $\begin{array}{l}\text { Count } \\
\% \text { within Ethic Group } \\
\% \text { within Respondent's gender } \\
\% \text { of Total } \\
\text { Count }\end{array}$ & $\begin{array}{l}18 \\
38.3 \% \\
12.2 \% \\
5.1 \% \\
9 \\
\end{array}$ & $\begin{array}{l}29 \\
61.7 \% \\
14.3 \% \\
8.3 \% \\
24 \\
\end{array}$ & $\begin{array}{l}47 \\
100.0 \% \\
13.4 \% \\
13.4 \% \\
33 \\
\end{array}$ \\
\hline & Coloured & $\begin{array}{l}\% \text { within Ethic Group } \\
\% \text { within Respondent's gender } \\
\% \text { of Total }\end{array}$ & $\begin{array}{l}27.3 \% \\
6.1 \% \\
2.6 \%\end{array}$ & $\begin{array}{l}72.7 \% \\
11.8 \% \\
6.9 \% \\
\end{array}$ & $\begin{array}{l}100.0 \% \\
9.4 \% \\
9.4 \%\end{array}$ \\
\hline
\end{tabular}

While many of the black respondents (53) were within the age group of 31-35 years, many of the white respondents were within the age group of 26-30 and had counted to a total of 26. As in the black ethnic group, the highest number of Indian respondents came from the age group of 14 (29.8), contributing $15.4 \%$ to the total number of the respondents in the age group of 31-35 years and only $4 \%$ to the total number (350) of the respondents. Contrary to this finding, the number of Coloured respondents were high $(13=39.4 \%)$ in age group of $26-30$ years, contributing $15.3 \%$ to the total number of respondents within the same age group and $3.7 \%$ to the total number of 350 respondents in the survey. It is interesting to note that all ethnic groups, with the exception of Indian ethnic group which have lower number of respondents in the age group of '15-20' and ' 36 years and older', had few respondents from the age group of 15-20 years.

The ethnic group with the lowest number of respondents was the Coloured people. These respondents were 33, 9 of which were males and 24 were females. The total number of Coloured male respondents contributed $27.3 \%$ to the total number of Coloured respondents irrespective of their gender, and $6.1 \%$ to the total number of 147 male respondents. Going further, the male coloured respondents contributed $2.6 \%$ to the total of 350 respondents irrespective of an ethnic group, regional hub, age group and gender. Coloured female respondents contributed with $72.7 \%$ to the total number of 33 coloured respondents, $11.8 \%$ to 203 female respondents, and $6.9 \%$ to all the 350 respondents.

\subsubsection{Students' uses of myUnisa}

The question that sought to determine whether students use myUnisa or not revealed that a larger number of the 
students amounting to a total of 228 (65.1\%) used myUnisa as a communication medium and 122 (34.9\%) did not. Of the 228 respondents who used myUnisa, 93 (40.7\%) were males while 135 (59.2\%) were females. Of those male respondents who used myUnisa, $52(55.9 \%)$ were at their second year level whilst 41 (44\%) were at third level. It was interesting to note that out of the 135 female respondents who indicated that they used myUnisa, $79(58.5 \%)$ of them were doing their second year while 56 (41.5\%) were at third year level.

Male respondents who reported that they do not use myUnisa amounted to a total of 54 which contributed $36.7 \%$ to the total male respondents, that is, 147 . The 131 second year respondents showed $65.1 \%$ contribution to the total number of 201 second year respondents. Similarly, respondents from the third year level showed the same percentage of $65.1 \%$ contributing to the total number of 149 third year respondents.

Question 8 sought to find out what myUnisa applications students use and respondents were asked to indicate which of myUnisa applications they use. The myUnisa applications which were listed in the questionnaire were academic records, bibliographical details, change password, edit registration, examination results, examination time table, financial tracking and study fees quotation.

Table 2: Uses of myUnisa as a communication channel

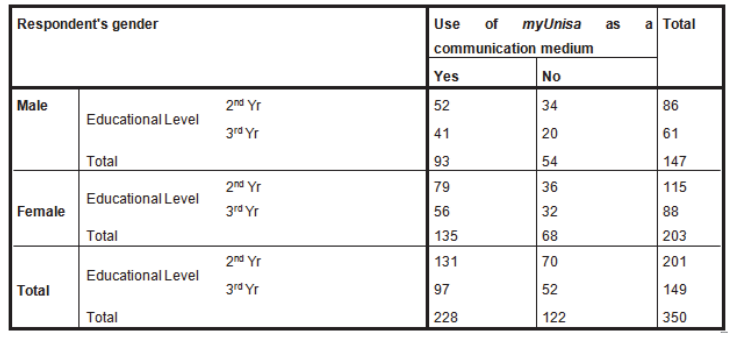

The graphic presentation (Levels of effectiveness of myUnisa) of the results shows that there were no respondents who considered myUnisa to be extremely non-effective. Of the 228 respondents who use myUnisa, there were only 4 respondents who reported that myUnisa is non-effective. This contributed $1.8 \%$ to the total number of those who use myUnisa and $1.1 \%$ of all the respondents in the study, including those who indicated that they do not use myUnisa. Those who considered myUnisa to be effective were 196 respondents. The contribution made by the 196 respondents to the total of 228 respondents who use myUnisa was $86 \%$. The same group of respondents who considered myUnisa to be effective contributed $56 \%$ to the total of 350 respondents in the study. While $21(9.2 \%)$ of 228 respondents and $6 \%$ of 350 respondents in the entire study) respondents indicated that myUnisa is less effective, only a proportion of 7 respondents indicated that they consider myUnisa extremely effective.

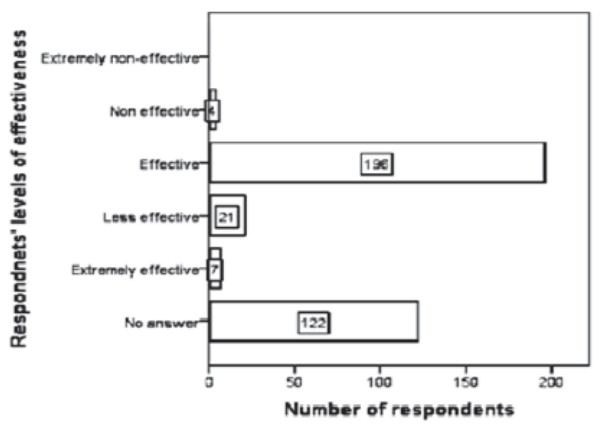

Figure 1: Levels of effectiveness of myUnisa

\subsubsection{General comments}

Question 23 which stated that: "In your opinion, what do you think UNISA should do to improve myUnisa?, revealed that there are lot of improvements that need to be done to make myUnisa an effective online learning system and a 
communication channel between the students and the variety of university structures. Many of the respondents pointed out technical problems such as 'information overload', and unavailability of myUnisa tool during crucial times such as when the students should send their assignments and examination portfolios. One of the respondents wrote in her questionnaire that "UNISA should work on improving the capacity and bandwidth of myUnisa to prohibit the problem of 'information overload' during the closing dates of the assignments. Otherwise myUnisa is not bad at all".

Other respondents stated that it seems as if myUnisa as a communication channel is not doing what it was designed for. As written by one of the respondents as follows: "I think myUnisa was designed to bridge the gap between the university and the students, and at the moment it is mostly a communication channel for one way communications that are in a form of announcements, advertisements, and delivery of study materials. UNISA should make it a two-way communication channel other than through online forums where very few students participate".

Other respondents raised the issue of time taken to open the myUnisa page. "It sometimes takes more time, approximately two to five minutes, to open the page and some of us are not patient as such. We end up not using it. UNISA should look for best possible solution to solve this problem", wrote one of the respondents.

The last section of the survey was the general comments and it focused on general opinions from the respondents on how myUnisa should be improved as well as other comments relating to the use of extranet in the higher education sector, particularly for the application in the students' learning process and more as a communication channel. The results revealed that there is a need to improve myUnisa. The extranet too should be considered vital in the learning process and should be one of the preferred learning systems. The results from the qualitative phase of this study validated that which were arrived at through quantitative phase. As have been shown in the quantitative phase, qualitative results reflected that although myUnisa as a communication channel is considered useful and important in the students' studies, there are areas in myUnisa tool that needs to be improved. For instance, the problem of information overload during the closing dates for assignments and examination portfolios must be crucially and critically looked at.

The "general comments section" of the questionnaire also generated information about the problems of effectively using myUnisa whereby it was stated that the use of myUnisa and some of its applications or tools requires certain skills such as basic computer literacy skills. This problem was once realised in other similar studies conducted prior to this one. These research findings supported Emmanuel and Ngiye (2011:230)'s findings in a similar study that online technology presents a challenge to the students because it requires basic computer literacy skills. Murphy and Cifuentes's (2001:285) study on using Web tools, collaborating and learning online in education institutions also found the same results. Respondents also mentioned that the use of myUnisa makes them feel isolated. They therefore suggested that the discussions classes must continue to be held.

\subsection{Findings: Qualitative phase}

This section presents findings from the in-depth interviews conducted with the academics, one of which was a women and the other one was a female, aged 30 and 27 respectively.

Findings from the qualitative phase are arranged in terms of themes as follows:

Theme 1: Uses and roles of myUnisa as a communication channel;

Theme 2: experiences and satisfactions of academics on myUnisa in their communications with the students;

Theme 3: challenges and problems on myUnisa as a communication medium; and

Theme 4: effectiveness of myUnisa in communications with the students.

\subsubsection{Uses and roles of myUnisa as a communication channel}

Findings from the in-interviews with the lecturers showed that myUnisa is used for student-lecturer communication. According to the participants, lecturers use myUnisa to communicate via online forums where they discuss with the students on different topics of a particular module. This finding corroborates with Tilwaldi, Takahashi, Takata and Koizumu (2010:36)'s study that students benefit from learning online with lecturer executing a guiding role. This is one of ways to communicate interactively to the students.

Other than this mode of communication taking place through myUnisa channel, the study discovered that lecturers use myUnisa for distributing information on the availability of student jobs such as the academic assistants, research assistants and administrative assistants. U\&G theory theorise that people use a particular media channel for certain reason and to fulfil certain needs and derive pleasure in doing so. One of the participants remarked: "myUnisa is quite pivotal in recruiting students for assistant positions such as research, administrative and academic assistants as well as for communications through online forums". 
In addition, the study also found that the type of communications that often occur through myUnisa is one-way to the students as compared to the two-way communications. This, in the view of one of the participants, is still a weakness of myUnisa portal. For example, one participant said: "The problem with myUnisa is that it serves as a source from which students get information about UNISA and their studies and not as a communication channel through which they can exchange messages with university departments except through forums". However, the overall view of the lecturers was that myUnisa is useful and beneficial and it supplements other channels to communicate with the students. Participants identified those channels to be the telephones, faxes, e-mails and the use of UNISA website for postings UNISA matters that also seeks the attentions of the students.

\subsubsection{Experiences and satisfactions of academics on myUnisa in their communications with the students}

myUnisa as communication channel is considered important in teaching and learning at UNISA. The experiences and the satisfactions of the students in using a particular technology to communicate or study are dependent upon various factors that impact on the students' performance. Hermans, Haytko and Mott-Stenerson (Sa:1) argue that there are three crucial aspects to consider for students and lecturers in an internet enhanced course. These authors identified them as satisfaction with the instructor, perceived ease of use of the course technology, and satisfaction with the course".

The findings in this study showed that lecturers have the positive experience of myUnisa. One of the interviewed lecturers said: "myUnisa is a good communication channel that enables interaction with the students anywhere they are, and at any time you want. We are able to send study materials in PDF to the students through the help of the ICT, announcements about the module students are registered for, advertisements of student jobs. Apart from these benefits we get, we are able to interactively communicate with them through online forums where topics are usually on a particular module for which students are registered."

Lecturers were also asked to give their views on the extent to which they are satisfied with myUnisa as a communication channel. Responses revealed that they were satisfied. It was also stated that students are able to access their study materials such as the tutorial letters and previous exam papers, and to send multiple choice assignments through myUnisa which makes myUnisa an important education delivery mode.

From these lecturers' responses, it is deducible that UNISA lecturers are satisfied with myUnisa and label it as good pedagogical mode for teaching and learning. They also consider it to be effective in learning, contributing to the success of the students.

\subsubsection{Challenges and problems on myUnisa as a communication medium}

All participants stated that myUnisa has problems and presents challenges, not only to the students but also to the lecturers who have to monitor the progresses of the students. Lecturers said it is difficult to access students in online forums available in myUnisa when there is no internet connection or when the electricity is down. One of the participants also mentioned that students like to wait until the last day for submission of the assignments and myUnisa is incapable to transmit those assignments to UNISA in a large number - an information overload. In an attempt to eliminate this kind of problem, as one of the participants puts it: "We always urge students to submit their assignments as early as possible because we know that myUnisa bandwidth is not able to carry a lot of assignments during those last days of submission."

It was also interesting to discover that some students make mistakes and submit the wrong assignments and later attempt to submit the right ones. myUnisa does not allow for the second submission unless if it is different assignment with different unique code. The findings also showed that sometimes it takes long for myUnisa pages to open; resulting in students feeling bored and personally come to the UNISA campuses for submission of the assignments.

\subsubsection{Effectiveness of myUnisa in communications with the students}

Drawing an overall conclusion upon the effectiveness of myUnisa, the lecturers' view was that myUnisa is an effective learning management system. In the words of one of the participants: "You see, as lecturers we get linked to the various modules we teach, enabling us to check the students information on the module for which he or she is doing. There, we can check the progress of the students in learning journey after which we can phone or send e-mails to guide the students on the specific module". According to the participants, this makes myUnisa an effective technology-based channel of communication for communications with the students. The study also found that indeed the lecturers do send announcements on specific modules to those students registered for that module through the ICT department. This finding contributed to forming a collective view that myUnisa is effective in communicating to the students. 
Another benefit myUnisa brings to the student-lecturer communications identified by the lecturers was that online forums on myUnisa provide platforms to communicate interactively on the topics of modules they are registered for. This helps to encourage them to be actively engaged in learning processes and ultimately make them successful in their studies. The study conducted by Hartman (1995) also presented the same findings that a student who is actively involved in the learning process is likely to be successful.

\section{Recommendations}

Given the nature of the findings of this study, it is recommendable for open distance learning institutions to take note of the following suggestions to ensure best practices and implementations of extranets for communications with their students.

- $\quad$ ODL institutions should expand the bandwidth of extranets to eliminate or reduce information overload;

- ODL institutions should encourage students who want to submit their assignments through extranets at least six to eight days prior to the due date for submission;

- ODL institutions should enable extranets to perform the retrieval of the wrong submitted assignments by the students or the denial of submission of wrong assignments. Students must be able to submit and resubmit the same assignment, possibly within a given short time-frame;

- future research should be focused on investigating the technical aspects of extranets and make improvements on them thereafter;

- there is a need to research the possibility of transforming extranets from being more of a one-way to two-way communication channels;

- There is a need for future research to be focused on the relationship between employees' level of education and communication satisfaction level on the use of extranets as communication channels in ODL institutions;

- Higher education institutions that use or intend to use extranets for their communication with the students should implement a HEl-student type of an extranet which puts student at a focal point

\section{Conclusion}

This research focused on the extranets in higher education institutions, investigating their roles, vitality and effectiveness in students' studies. The study used a case study of the University of South Africa's (UNISA) extranet as a fundamental foundation of arguments and as an epitome of the developed and applied extranet in Higher Education Institutions. Approaching this study from a communication perspective and focusing on the extranet as a communication channel for the delivery of education between the students and the university structures and amongst the students themselves, it was learned that the extranet is becoming increasingly useful, facilitating the process to teach and learn as a technologyoriented mode.

The literature review also proved that there is no universal definition of the extranet. An extranet was defined by Hannon (1998) as any network linked to another network in order to allow the sharing of information and data, and which exists when two business partners link their intranets to each other for business communication and transactions. Hannon's definition did not suit the current situation of myUnisa. Instead, myUnisa as an extranet and an electronic communication channel is understood and better defined by Angeles (2001:168) who argues that an extranet is an organisation's intranet which provides access of information to the outside stakeholder of the host. Angeles's definition slightly qualifies to describe an extranet within the myUnisa context merely because students who access UNISA's information are UNISA's external stakeholders. What exacerbates complexity on understanding and referring myUnisa as an extranet was that, not only do students access UNISA's information but also exchange educational information through online forums. This makes myUnisa an extranet of its own kind. However, because the results of this study showed that myUnisa has been understood to be more of a one-way communication (from UNISA to the students in form of announcements, for instance) than a two-way communication (between UNISA and the students or amongst the students themselves through online forums), it can be deduced that myUnisa does not or did not meet UNISA's goal of enabling communications between its various structures and the students. It should, therefore, be redesigned and improved to allow more two-way communications with all UNISA's structures.

The research also reflected that the extranet can be developed for various reasons and can take many forms depending on the purpose for which they are developed and implemented. 


\section{References}

Angeles, R. (2001). Creating a digital marketplace presence: lessons in extranet implementation. Internet Research: Electronic Networking Applications and Policy, 11(2): 167-184.

Babbie, E. and Mouton, J. (2001). The practice of Social Research. Southern Africa: Oxford University Press.

Bazeley, P., 2009. Editorial: Integrating Data Analysis in Mixed Methods Research. Journal of Mixed Methods Research, 3(3): 203-207.

Cameron, D.I (1998). E-commerce Security Strategies, Computer Technology Research Corp: Charleston, SC.

Creswell, J. W., Plano Clark, V. L., Gutmann, M. L., \& Hanson, W. E. (2003). Advanced mixed methods research designs. In A. Tashakkori \& C. Teddlie (Eds.), Handbook of mixed methods in social and behavioral research , 209-240. Thousand Oaks, CA: Sage.

Cummings, N.M. (2008). The uses and Gratifications of Communication in virtual spaces: Media Depictions of Second Life: $2002-2008$. Available at: <https://scholarsbank.uoregon.edu/xmlui/bitstream/handle /1794/8987/Cumming_Nicholas_Michael_BA2008.pdf? sequence $=1>$ [Accessed 13 March 2013].

Emmanuel, S.C., and Ngiye, M.G. (2011). Online Teaching of Languages: A case study of Moi University, Kenya. Journal of Language, Technology \& Entrepreneurship in Africa, 3(1): 223-243.

Flanagin, A. J. and Metzger, M. J. (2001). Internet use in the contemporary media environment. Human Communication Research, 27, pp. 153-1 81.

Green, J.C. (2007). Mixed methods in social inquiry. San Francisco, CA: Jossey-Bass.

Green, J.C. (2008). Is mixed methods social inquiry a distinctive methodology? Journal of Mixed Methods Research (2): 7-22.

Hannon, N.J. (1998). The Business of the internet, Course Technology: New York, NY.

Hartman, V. F. (1995). Teaching and learning style preferences: Transitions through technology. VCCA Journal, $9(2): 18-20$.

Healy, M. and Iles, J., (2002. The Establishment and Enforcement of Codes. Journal of Business Ethics (39): 117-124.

Hermans, C.M., Haytko, D.L. and Mott-Stenerson, B., [n.d.]. Student Satisfaction in Web-enhanced Learning Environments. Journal of instructional pedagogies. Available at: <http://www.aabri.com/manuscripts/09147.pdf > [Accessed 09 June 2013].

Hesse-Bibber, S.N. (2010). Mixed method research; Merging theory with practice. New York: Guide Press.

Ivankova, N.V., Creswell, J.W. and Stick, S.L. (2006). Using Mixed-Methods Sequential Explanatory Design: From Theory to Practice. Field Methods, 18(1): 3-20.

Johnson, B., \& Onwuegbuzie, A. (2004). Mixed methods research: A research paradigm whose time has come. Educational Researcher, 33 (7): 14-26.

Johnson, R.B., Onweugbuzie, A.J. and Turner, L. A. (2007). Toward a definition of mixed methods research. Journal of Mixed Methods Research, (1): 112-133.

Leung, L. and Wei, R. (2000). More than just talk on the move: Uses and Gratifications of the Cellular Phone. Journalism \& Mass Communication Quarterly, 77(2): 308-320.

Maier, P.Q. (2013). Ensuring Extranet Security and Performance. Information Systems Management, 17(2): 1-8.

Mills, A. (1998). Extranet-based Business Models. Centre for Research on the Applications of Telematics to Organisations and Society: $1-22$.

Murphy, K.L. and Cifuentes, L. (2001). Using Web tools, collaborating, and learning online. Distance Education, 22(2): 285-305.

Netanda, R.S. (2012). Mixed-methods Triangulation War: Hidden challenges to their conceptual survival in

International Handbook of Academic Research and Teaching, Proceedings of Intellectbase International Consortium (22): $343-349$.

Netanda, R.S. (2013). Effectiveness of the extranet as a communication tool in higher education: A case study of

university of South Africa. Masters dissertation in communication Science, University of Zululand (UNIZULU): 1-182.

Oppong, S.A., Yen, D.C., and Merhout, J.F. (2005). A new strategy for harnessing knowledge management in e-commerce. Technology in Society (27): 413-435.

Papacharissi, Z., and Rubin, A. M. (2000). Predictors of Internet usage. Journal of Broadcasting \& Electronic Media (44): $175-196$.

Raacke, J. and Bonds-Raacke, J. (2008). MySpace and Facebook: Applying the uses and gratifications Theory of Exploring friendNetworking Sites. Cyber Psychology \& Behaviour, 11(2): 169-174.

Rainer, R.K., and Cegielski, C.G. (2009). Introduction to information Systems: Enabling and Transforming Business.

Riggins, F.J. and Rhee, H. (1998). Toward a unified view of electronic commerce: Association for Computing Machinery. Communications of the ACM, 14(10): 88-95.

Shao, G. (2009). Understanding the appeal of user-generated media: A uses and gratification perspective. Internet Research, 19 (1): 725.

Tilwaldi, D., Takahashi, T., Takata, A., and Koizumu, H. (2010). A Cooperative Distance learning Method Based on Narrow-Based Internet and its Evaluation. Electronics and Communications in Japan, 93 (4): 253-263.

Truscott, D. M, Swars, S, Smith, S, Thornton-Reid, F, Zhao, Y, Dooley, C, Williams, B, Hart, L. and Matthews, M. (2010). A crossdisciplinary examination of the prevalence of mixed methods in educational research: 1995-2005, International Journal of Social Research Methodology, 13(4): 317-328.

Vlosky, R., Fontenot, R. and Blalock, L. (2000). Extranets: impacts on business practices and relationships. Journal of Business \& Industrial Marketing, 15(6): 438-457. 